\title{
Lipidomics in Ulcerative Colitis Reveal Alteration in Mucosal Lipid Composition Associated with the Disease State
}

Joseph Diab, MSc, ${ }^{\text {a }}$ Terkel Hansen, PhD, ${ }^{\text {a }}$ Rasmus Goll, PhD, MD,,${ }^{\text {b c }}$ Hans Stenlund, PhD, ${ }^{d}$ Maria Ahnlund, PhD, ${ }^{\mathrm{d}}$ Einar Jensen, $\mathrm{PhD},{ }^{\mathrm{a}}$ Thomas Moritz, $\mathrm{PhD},{ }^{\mathrm{c}}$ Jon Florholmen, $\mathrm{PhD}, \mathrm{MD},{ }^{\mathrm{b}, \mathrm{c}}$ and Guro Forsdahl, $\mathrm{PhD},{ }^{\mathrm{a}}$

a Natural Products and Medicinal Chemistry Research Group, Department of Pharmacy Faculty of Health Sciences, University of Troms $\varnothing$ The Arctic University of Norway, Troms $\varnothing$, Norway

${ }^{b}$ Research Group of Gastroenterology and Nutrition, Department of Clinical Medicine Faculty of Health Sciences, University of Troms $\varnothing$ The Arctic University of Norway, Troms $\emptyset$, Norway

${ }^{\mathrm{c}}$ Department of Medical Gastroenterology, University Hospital of North Norway, Troms $\emptyset$, Norway ${ }^{d}$ Swedish Metabolomics Center, Department of Molecular Biology, Umeå University, Umeå, Sweden

Corresponding author: Guro Forsdahl.

Department of pharmacy, University of Troms $\emptyset$ The Arctic University of Norway Muninbakken 11, 9019, Troms $\varnothing$, Norway

Guro.forsdahl@uit.no

$+4791561129$

This project was funded by the Northern Norway Regional Health Authority [SFP-1134-13], and university of Tromsø the arctic university of Norway.

Summary: The lipidomics analysis of mucosal lipids in UC patients revealed disruption in lipid composition pattern in active and deep remission UC. Several lipids seem to be involved in the inflammatory processes in UC, and could reflect the disease state. 


\begin{abstract}

\section{Background}

The onset of ulcerative colitis (UC) is associated with alterations in lipid metabolism, and a disruption of the balance between pro and anti-inflammatory molecules. Only a few studies describe the mucosal lipid bio-signatures during active UC. Moreover, the dynamics of lipid metabolism in the remission state is poorly defined. Therefore, this study aims to characterize mucosal lipid profiles in treatment-naive UC patients, and deep remission UC patients, compared to healthy subjects.
\end{abstract}

\title{
Methods
}

Treatment-naive UC patients $(n=21)$, UC patients in deep remission $(n=12)$, and healthy volunteers $(n=14)$ were recruited. The state of deep remission was defined by histological and immunological remission defined by a normalized TNF- $\alpha$ gene expression. Mucosa biopsies were collected by colonoscopy. Lipid analysis was performed by means of ultra-high performance liquid chromatography coupled with tandem mass spectrometry (UPLC-MS-MS). In total, 220 lipids from 11 lipid classes were identified.

\section{Results}

The relative concentration of 122 and 36 lipids was altered in UC treatment-naïve patients and UC remission patients, respectively, compared with healthy controls. The highest number of significant variations were in phosphatidylcholines (PC), ceramides (Cer), and sphingomyelin (SM) composition. Multivariate analysis revealed discrimination among the study groups based on the lipid profile. Furthermore, changes in PE(38:3), Cer(d18:1/24:0), and Cer(d18:1/24:2), were most distinctive between the groups.

\section{Conclusion}

This study revealed alteration in mucosal lipid composition pattern in treatment-naïve UC and deep remission UC. We report several distinctive lipids, which might be involved in the inflammatory response in UC, and could reflect the disease state.

\section{Key Words}

Inflammatory bowel disease; Lipidomics; Ulcerative colitis; Phospholipids; Sphingolipids. 


\section{1- Introduction}

Inflammatory bowel diseases (IBD) are chronic, relapsing inflammatory disorders in the gastrointestinal tract that affects around 1.6 million in the United States and 2.2 million in Europe ${ }^{1}$. The two major forms of IBD, ulcerative colitis (UC) and Crohn's disease (CD), are characterized by a dysregulated mucosal immune response triggered by the intestinal commensal flora ${ }^{2}$. Several genetic, bacterial, and environmental factors appear to lead to the onset of IBD. However, the etiology of IBD is not fully understood $^{3}$. The main treatments of IBD involve steroids and immune-suppressive/modulatory medications $^{4}$, such as anti-TNF- $\alpha$ in severe cases. However, $20-30 \%$ of UC patients need surgery at some point during their lifetime due to treatment failure or disease complications ${ }^{5}$, whereas $50-65 \%$ of UC patients might achieve remission ${ }^{6}$. Nonetheless, since there is no agreement on the definition of ‘complete remission' state, IBD patients might relapse after de-escalating medical treatment ${ }^{7}$.

Membrane bio-active lipids modulate the immune response by functioning as intra- and intercellular signaling molecules ${ }^{8}$. For instance, sphingolipids and phospholipids are involved in controlling cellular processes, such as proliferation, migration, apoptosis, differentiation, and pro-inflammatory cytokine release $^{9,10}$. Accordingly, the chronic inflammation seen in IBD is characterized by a disruption of the balance between pro- and anti-inflammatory molecules ${ }^{11}$. Consequently, UC seems to be associated with alterations in the lipid metabolism ${ }^{12,13}$. Furthermore, we have recently demonstrated major changes in the mucosal concentration of poly-unsaturated fatty acid (PUFA) metabolites in treatment naive UC patients ${ }^{14}$.

'Lipidomics' is defined as the study of the lipids metabolism, composition, and distribution on a large scale in a given organism ${ }^{15}$. Lipidomics has become a powerful tool to understand the pathology and to predict the prognosis of complex inflammatory diseases such as, diabetes mellitus ${ }^{16,}{ }^{17}$, multiple sclerosis $^{18}$, arthritis ${ }^{19}$, and Alzheimer disease ${ }^{20}$. However, there are few IBD studies describing mucosal lipid bio-signatures.

This study aims to describe the mucosal lipid profile in treatment naive UC patients and deep remission UC patients compared with healthy subjects. The high throughput lipidomics analysis will help capturing the main mucosal lipid composition changes, which reflect the inflammatory state in active UC and treatment-induced deep remission UC. 


\section{2- Materials and Methods}

\section{2-1-Patients and biopsy collection}

Mucosal biopsies were collected from newly diagnosed treatment naive UC patients $(n=21)$ and UC patients in deep remission $(\mathrm{n}=12)$. The UC diagnosis was established upon clinical, endoscopic and histological criteria defined by the European Crohn and Colitis Organization (ECCO) guidelines. ${ }^{21}$ The degree of inflammation was evaluated during colonoscopy using the scoring system of ulcerative colitis disease activity index (UCDAI); UCDAI score of 3-5 is defined as mild, 6-8 as moderate, and 9-12 as severe $\mathrm{UC}^{22}$. TNF- $\alpha$ mRNA expression levels were measured by real-time PCR in mucosal biopsies, to evaluate the UC activity ${ }^{23}$. The state of deep remission was defined as endoscopic healed mucosa by ECCO 2017 consensus (Mayo score $=0)^{24}$ and, additionally, normalized mucosal TNF- $\alpha$ level induced by anti-TNF- $\alpha$ treatment ${ }^{25}$. Subjects performing endoscopy for colonic malignancy screening, with normal findings and normal colonic histological examination, served as healthy controls $(n=14)$.

The biopsies from UC treatment naive patients and the UC remission group were obtained from the rectum or sigmoid colon. In patients with active UC, biopsies were taken from the most inflamed mucosa, whereas biopsies from the control group were obtained from the rectum. The dry weight of the biopsies ranged from $2-8 \mathrm{mg}$. All biopsies were dry-frozen immediately at $-70^{\circ} \mathrm{C}$, and kept at this temperature until further analysis.

\section{2-2-Chemicals and reagents}

N-palmitoyl- $\mathrm{d}_{31}$-D-erythro-sphingosine (16:0-d31 ceramide) was obtained from Avanti Polar Lipids (Alabaster, AL, USA). Tripalmitin-1,1,1-13 $\mathrm{C}_{3}\left(\mathrm{TG}(16: 0 / 16: 0 / 16: 0)-{ }^{13} \mathrm{C}_{3}\right)$ was purchased from Larodan (Solna, Sweden). Acetonitrile, formic acid, ammonium formate, chloroform and methanol were HPLC grade or higher and purchased from Merck (Darmstadt, Germany). Isopropanol was obtained from VWR International (Stockholm, Sweden). Water was purified by a Milli-Q gradient system (Millipore, Milford, MA, USA).

\section{2-3-Lipid Extraction}

Lipid extraction was carried out using a modified Folch extraction ${ }^{26}$. Briefly, each biopsy was transferred to an Eppendorf tube and kept on ice. Then, the extraction mixture (chloroform:methanol $2: 1 \mathrm{v} / \mathrm{v}$, including both internal standards tripalmitin- $1,1,1-{ }^{13} \mathrm{C}_{3}$ and $16: 0-\mathrm{d} 31$ ceramide) was added to 
the biopsy in a solid-to-solvent ratio of 1:50 (w/v). The final concentration of tripalmitin-1,1,1- ${ }^{13} \mathrm{C}_{3}$ and tube, and the samples shaken at $30 \mathrm{~Hz}$ for $3 \mathrm{~min}$, and stored at room temperature for 30-60 min. The beads were removed, and the samples were further centrifuged at $14,000 \mathrm{rpm}$ and $4{ }^{\circ} \mathrm{C}$ for $3 \mathrm{~min}$. Finally, the organic phase was collected, split in half and transferred to two micro vials. Samples were dried using a vacuum concentrator (MIVac, SP, Warminster, PA, USA) reconstituted in $50 \mu \mathrm{L}$ of acetonitrile. Extracts were stored at $-80{ }^{\circ} \mathrm{C}$ until analysis.

\section{2-4-Lipidomics analysis}

Lipidomics analysis was performed with an Infinity 1290 Agilent (Agilent Technologies, Santa Clara, CA, USA) ultra-high performance liquid chromatograph coupled with tandem mass spectrometry (UHPLC-MS-MS) as previously described ${ }^{26,27}$. Briefly, $1 \mu \mathrm{L}$ of each extract was injected into the UHPLC system equipped with an Acquity column $(\mathrm{CSH}, 2.1 \times 50 \mathrm{~mm}, 1.7 \mu \mathrm{m}$ C18 in combination with a $2.1 \mathrm{~mm} \times 5 \mathrm{~mm}, 1.7 \mu \mathrm{m}$ VanGuard CSH precolumn (Waters Corporation, Milford, MA, USA), held at $60{ }^{\circ} \mathrm{C}$. The gradient elution buffers were A (60:40 acetonitrile: water, $10 \mathrm{mM}$ ammonium formate containing $0.1 \%$ formic acid) and $\mathrm{B}$ (90:10 2-propanol: acetonitrile, $10 \mathrm{mM}$ ammonium formate containing $0.1 \%$ formic acid). $15 \% \mathrm{~B}$ at a flow rate of $0.5 \mathrm{~mL} / \mathrm{min}$ was set as initial condition, and the following gradient was used: B was increased to $30 \%$ in $1.2 \mathrm{~min}$, then to $55 \%$ in $0.3 \mathrm{~min}$ and held at 55 $\%$ for $3.5 \mathrm{~min}$. It was progressively increased as follows: $72 \%$ in $2 \mathrm{~min}$, then $85 \%$ in $2.5 \mathrm{~min}$ and to $100 \%$ in 0.5 min and was held for 2 minutes. The exact masses of individual lipid molecules were detected with an Agilent 6550 Q- TOF mass spectrometer equipped with an iFunnel jet stream electrospray ion source (Agilent Technologies, Santa Clara, CA, USA). The first batch of extracts was analyzed in positive mode. Then, the instrument was switched to the negative mode and the second batch of extracts was injected. The flow gas temperature was set at $150^{\circ} \mathrm{C}$, the drying gas flow at $12 \mathrm{~L}$ $\min ^{-1}$ and the nebulizer pressure at $40 \mathrm{psi}$. The sheath gas temperature was set at $350^{\circ} \mathrm{C}$ and the sheath gas flow $1 \mathrm{~L} \mathrm{~min}^{-1}$. The capillary voltage was set at $4000 \mathrm{~V}$ for the positive mode and $2300 \mathrm{~V}$ for the negative mode. The $\mathrm{m} / \mathrm{z}$ range was $70-1700$, and data were collected in centroid mode with an acquisition rate of 4 scans/s. 
Targeted data processing was performed using Agilent MassHunter ProFinder B.08.00 software,

whereas in- house databases with exact masses and experimental retention times were used for identification. Finally, the extracted features were aligned and matched between samples. In total, 220 lipid species were identified. These lipid species were from the following lipid classes and subclasses: dihydroceramide (dhCer), galactosylceramide (GalCer), ceramide (Cer), sphingomyelin (SM), phosphatidylethanolamine (PE), phosphatidylcholine (PC), phosphatidylserine (PS), phosphatidylinositol (PI), phosphatidylglycerol (PG) lysophosphatidylethanolamine (LPE), and lysophosphatidylcholine (LPC). Results were expressed as area under the curve (AUC) values from the extracted ion chromatograms of each lipid molecule. Peak areas of individual lipid species were normalized by the sum of peak areas of all detected lipid species in the same lipid class. Hence, quantitative data for each lipid specie was expressed in percentage as relative concentration to the total amount of lipids in the same respective lipid class.

\section{2-5-Statistical analysis}

Statistical analysis was carried out using MetaboAnalyst 4.0, a web tool for metabolomics data analysis (http://www.metaboanalyst.ca/) ${ }^{28}$. Undetectable lipids, which represented $1.2 \%$ of total reported lipids, were assigned a value corresponding to half of the minimum positive value in the original data. ShapiroWilk test of normality was applied, and the data was not found normally distributed. Kruskal-Wallis one way analysis of variance test was performed to determine the differences of lipid species between treatment naïve UC, remission UC, and control groups. Acquired $p$-values were adjusted using Benjamini and Hochberg FDR method ${ }^{29}$. Dunn's test ${ }^{30}$ was applied as a post hoc test, and significant $p$ value cut-off was corrected to 0.017 by Bonferroni multiple comparison method ${ }^{31}$. The relative lipid concentrations were auto scaled in order to adjust the importance of high and low abundance lipids to an equal level, and to ease the comparison between the relative lipid concentrations among the study groups $^{32}$. Multivariate analysis was carried out using SIMCA software (version 14.0.0.135559; Umetrics AB, Umea, Sweden). Unsupervised multivariate analysis principle component analysis (PCA) was first performed to assess the unicity of the lipidome for each of the study group. Then, supervised orthogonal partial least squares projection to latent structures-discriminant analysis (OPLS-DA) was employed and shared and unique plots (SUS-plot) ${ }^{33}$ were generated to identify the main lipids responsible for the 
discriminant lipid profile associated with UC treatment-naïve patients. The parameters of the OPLS-DA model were described by $R^{2} \mathrm{X}_{\text {cum }}, R^{2} \mathrm{Y}_{\text {cum }}$ and $\mathrm{Q}^{2}$ cum, whereas, $R^{2} \mathrm{X}_{\text {cum }}$ is the cumulative modeled variation in $\mathrm{X}, R^{2} \mathrm{Y}_{\text {cum }}$ is the amount of variation in $\mathrm{X}$ correlated to $\mathrm{Y}$ (response matrix) and $\mathrm{Q}^{2}$ cum is the cumulative predicted ability of the model ${ }^{34}$.

\section{3- Ethical Considerations}

The Regional Committee of Medical Ethics of North Norway and the Norwegian Social Science Data Services approved the study and the storage of biological material under the number (REK NORD 2012/1349). In addition, all enrolled subjects have signed an informed consent form.

\section{4- Results}

\section{4-1-Subjects Characteristics}

In total, 21 newly diagnosed treatment naive UC patients, 12 UC patients in state of deep remission and 14 healthy controls were enrolled in this study. The study group characteristics are described in Table 1. The UC patients' disease activity was ranging from mild to severe; 11 patients had mild UC, 4 patients had moderate UC and 6 patients had severe UC.

\section{4-2-Mucosal lipid profiles in treatment-naive UC patients, UC remission patients and controls}

Mucosal lipid profiles in colon biopsies were assessed to determine significant changes in lipid composition in treatment naive patients and UC deep remission patients compared to controls.

Kruskall-Wallis one way analysis of variance with Dunn post hoc was used to compare lipid concentrations between all three groups (supplementary Table 1). As summarized in Table 2, among the 220 lipids included in this study, the relative concentration of 122 and 67 lipids were altered in UC treatment naïve patients compared with healthy controls and with UC remission patients respectively. However, the mucosal relative concentration of only 26 lipids was changed in UC remission patients compared with healthy controls. The lipid classes with the highest number of significant variation in the lipid composition were PC, Cer, and SM.

The greatest change was in the relative mucosal concentration of $\operatorname{PE}(38: 3)$, which was increased by 37 fold in inflamed mucosa compared with healthy mucosa (supplementary Table 1). 


\section{4-3-Discriminative models for UC state}

The PCA was used as an unbiased multivariate analysis to assess the distinctive lipidomic profile for each of the study groups. The PCA score plot (Figure 1A) revealed a clear separation between naïve treatment UC patients and healthy controls indicating a specific lipidomic profile for active UC patients. However, PCA did not reveal a distinct lipidomic profile for UC remission patients. In addition, PCA provided no separation of patients according to age, sex or activity score (data not shown). A supervised OPLS-DA was applied to assess the discriminative power of the mucosal lipid profile for UC patients (in active and remission state) and healthy controls. A significant OPLS-DA model was obtained with maximum separation between the study groups (Figure 1B). The performance parameters describing the fitness of all multivariate data analysis models in this study are described in table 3.

\section{4-4-Discriminative lipids for UC state}

Two OPLS DA models were built, UC treatment-naive vs healthy controls and UC treatment-naive vs UC remission. The score plots corresponding to these models are shown in Figures 1C and 1D respectively. The shared and unique structure (SUS) plot, constructed from the loading plots of these models, identified the main lipid composition pattern in treatment naïve UC patients (Figure 2A). The SUS plot revealed that the lipidomic profile in UC treatment-naïve patients is mainly characterized by high levels of very long fatty acid chain (VLCFA) ceramides, specifically those with 24 carbons chainlength (C24). In addition, several PCs and PEs were elevated, mainly PE(38:3).

Based on the SUS-plot, 3 candidate lipids were selected for further investigation. These lipids were $\operatorname{PE}(38: 3)$, Cer(d18:1/24:0), and $\operatorname{Cer}(\mathrm{d} 18: 1 / 24: 2)$. The discriminative ability of these lipids was confirmed by comparing the ion chromatograms at the specific retention times (RT) for each of these lipids among the study groups. As shown in Figure 2, PE(38:3) was only detected in UC patients colonic mucosa (both UC active and UC remission patients). Moreover, $\operatorname{PE(38:3)~is~clearly~increased~in~}$ inflamed mucosa (UC active) compared with healed mucosa (UC remission). In addition, the levels of $\operatorname{Cer}(\mathrm{d} 18: 1 / 24: 0)$ and $\operatorname{Cer}(\mathrm{d} 18: 1 / 24: 2)$ were low in healed mucosa, and increased in a step wise manner in UC remission patients and treatment-naïve UC patients. 


\section{5-Discussion}

This study provides a unique and detailed characterization of mucosal lipid profiles in treatment naive newly diagnosed and deep remission UC patients. Previous studies were restricted to investigate lipid profiles in other matrices, specifically plasma ${ }^{35}$ and stool ${ }^{36}$ or in animal models with experimentally induced colitis ${ }^{37}$. Moreover, previous studies were performed on a mix of treated and untreated UC patients, which might lead to less specific profiles, regarding the differences between active disease and remission demonstrated in the present data. Therefore, only treatment naive UC patients were recruited as active inflammation group in our study. The state of remission was based on a combination of normalized TNF gene expression, histologic, and endoscopic criteria (Mayo $=0$ ). This allows the detection of variations in the lipid composition that are exclusively associated with UC development. To our knowledge, this is the first published study of mucosal lipid profiles in UC patients. We have investigated 220 lipids from 11 different lipid classes. The lipid profiling revealed major disruption in the mucosal lipid composition in active UC patients compared with healthy controls.

The most significant finding in the current study is the observed changes in the $\mathrm{PE}(38: 3)$ concentration in response to the mucosal inflammatory state. This lipid was only detected in the UC patients' mucosa. Notably, the mucosal levels consistently decrease in the remission state compared with the active disease state. Despite being poorly described in UC, high level of serum $\operatorname{PE}(38: 3)$ was previously found associated with diabetes and prediabetes ${ }^{38}$. Moreover, increased level of PE has been linked with Alzheimer disease ${ }^{39}$. In addition, due to the role of PE in apoptosis, PE has been suggested as a target for cell death imaging, and a marker for TNF-induced inflammation ${ }^{40,41}$. The plausible role of $\operatorname{PE}(38: 3)$ in promoting inflammation could make it useful in monitoring the development of UC. However, this needs to be confirmed by larger studies, which also investigate the presence of $\mathrm{PE}(38: 3)$ in other kinds of matrices such as feces, serum, or urine.

In the present data, Cer(d18:1/24:2) and Cer(d18:1/24:0) increase according to the UC state from remission to active inflammation. These two ceramides, classified as very long chain fatty acid sphingolipids (VLCFAs), are necessary for the neutrophils functions ${ }^{42}$. The present research is the first report highlighting the importance of VLCFA ceramides in UC, although they have been reported 
involved in other inflammatory diseases. For instance, higher levels of Cer(d18:1/24:2) and Moreover, a high serum level of $\operatorname{Cer}(\mathrm{d} 18: 1 / 24: 0)$ has been associated with a high risk of dementia in Alzheimer disease, and increased with the disease severity ${ }^{44}$.

The highest significant variations in the lipid composition were detected in Cer, SM and PC profiles. Previously, lipids analysis on experimentally induced IBD have revealed changes in sphingolipids (Cer and $\mathrm{SM})^{45}$ and the PC profile ${ }^{46}$. Changes in the PC profile demonstrate the impairment in the mucus barrier during $\mathrm{IBD}^{47}$. Furthermore, changes in sphingolipids could be explained by the suggested harmful role of ceramides in IBD, mainly by activating immune cells and triggering apoptosis ${ }^{9}$. Consequently, tissue ceramide levels were found elevated in a stepwise manner from control to remission, mild, and moderate/severe IBD patients ${ }^{48}$. In addition, it has been previously found that IL1 stimulates ceramide accumulation in intestinal epithelial cells ${ }^{49}$. Moreover, previous studies revealed major changes in sphingolipid metabolic pathways during IBD $^{50,51}$. The current study has revealed a distinct lipid profile in UC deep remission patients, although being selected based on mucosal healing and immunological remission ${ }^{52}$. Accordingly, the mucosal concentrations of 26 lipid species, mainly sphingolipids, were altered compared to healthy control. This finding could be of clinical utility in defining treatment goals and end-point parameters in the context of personalized medicine. Furthermore, it supports previously published data on the sphingolipid metabolism as a therapeutic target in $\operatorname{IBD}^{53,54}$. Moreover, this suggests the lipidomics profiling as a tool to improve the definition of UC remission in the current guidelines and scoring systems.

The present work is purely descriptive. Moreover, the relatively small sample size in the current study disqualify subgroup analysis according to the severity of the diseases. Furthermore, the reported results are expletory and need to be validated by a larger cohort. In addition, we suggest exploring the mucosal lipid profile using targeted analytical approaches allowing the absolute quantification of the studied lipids. 


\section{6-Conclusion}

The present report describe an in depth the mucosal lipid profile in UC via full lipidomic analysis of colon biopsies taken from UC treatment naive patients, UC patients in state of deep remission, and healthy subjects. The analysis of mucosal lipids demonstrated alteration in the lipid composition in active and deep remission UC, and it revealed the involvement of several lipids in the mucosal inflammatory processes in UC.

\section{Acknowledgments}

We thank Renate Meyer for administrating the patient samples. The Northern Norway Regional Health Authority [SFP-1134-13], and university of Troms $\emptyset$ the arctic university of Norway funded this project. 


\section{Reference}

1. M'Koma AE. Diagnosis of inflammatory bowel disease: Potential role of molecular biometrics. World J Gastrointest Surg 2014;6:208-19.

2. Molodecky NA, Kaplan GG. Environmental Risk Factors for Inflammatory Bowel Disease. Gastroenterol Hepatol (N Y) 2010;6:339-346.

3. Ananthakrishnan AN, Bernstein CN, Iliopoulos D, et al. Environmental triggers in IBD: a review of progress and evidence. Nature Reviews Gastroenterology \&Amp; Hepatology 2017;15:39.

4. Bernstein CN. Treatment of IBD: Where We Are and Where We Are Going. The American Journal Of Gastroenterology 2014;110:114.

5. Ferrari L, Krane MK, Fichera A. Inflammatory bowel disease surgery in the biologic era. World Journal of Gastrointestinal Surgery 2016;8:363-370.

6. Actis GC, Pellicano R. Inflammatory bowel disease: Efficient remission maintenance is crucial for cost containment. World journal of gastrointestinal pharmacology and therapeutics 2017;8:114-119.

7. Bryant RV, Winer S, Spl T, et al. Systematic review: Histological remission in inflammatory bowel disease. Is 'complete' remission the new treatment paradigm? An IOIBD initiative. Journal of Crohn's and Colitis 2014;8:1582-1597.

8. Shores DR, Binion DG, Freeman BA, et al. New Insights into the Role of Fatty Acids in the Pathogenesis and Resolution of Inflammatory Bowel Disease. Inflammatory bowel diseases 2011;17:2192-2204.

9. Bryan P-F, Karla C, Edgar Alejandro M-T, et al. Sphingolipids as Mediators in the Crosstalk between Microbiota and Intestinal Cells: Implications for Inflammatory Bowel Disease. Mediators of Inflammation 2016;2016:9890141. 
10. Sewell GW, Hannun YA, Han X, et al. Lipidomic profiling in Crohn's disease: Abnormalities in phosphatidylinositols, with preservation of ceramide, phosphatidylcholine and phosphatidylserine composition. The International Journal of Biochemistry \& Cell Biology 2012;44:1839-1846.

11. Das UN. Inflammatory bowel disease as a disorder of an imbalance between pro- and anti-inflammatory molecules and deficiency of resolution bioactive lipids. Lipids Health Dis 2016;15:11-18.

12. Masoodi M, Pearl DS, Eiden M, et al. Altered colonic mucosal Polyunsaturated Fatty Acid (PUFA) derived lipid mediators in ulcerative colitis: new insight into relationship with disease activity and pathophysiology. PLoS One 2013;8:e76532.

13. Schniers A, Goll R, Pasing Y, et al. Ulcerative colitis: functional analysis of the in-depth proteome. Clinical Proteomics 2019;16:4.

14. Diab J, Al-Mahdi R, Gouveia-Figueira S, et al. A Quantitative Analysis of Colonic Mucosal Oxylipins and Endocannabinoids in Treatment-Naïve and Deep Remission Ulcerative Colitis Patients and the Potential Link With Cytokine Gene Expression. Inflammatory Bowel Diseases 2018:izy349-izy349.

15. Lydic TA, Goo YH. Lipidomics unveils the complexity of the lipidome in metabolic diseases. Clin Transl Med 2018;7:4.

16. Suvitaival T, Bondia-Pons I, Yetukuri L, et al. Lipidome as a predictive tool in progression to type 2 diabetes in Finnish men. Metabolism 2018;78:1-12.

17. Pinz I, Robich MP, Ryzhov S, et al. A Novel Lipidomic Approach to Understand Human Diabetic Heart Disease. The FASEB Journal 2017;31:883.19-883.19.

18. Bergholt MS, Serio A, McKenzie JS, et al. Correlated Heterospectral Lipidomics for Biomolecular Profiling of Remyelination in Multiple Sclerosis. ACS Cent Sci 2018;4:39-51. 
19. Surowiec I, Ärlestig L, Rantapää-Dahlqvist S, et al. Metabolite and Lipid Profiling of Biobank Plasma Samples Collected Prior to Onset of Rheumatoid Arthritis. PLOS ONE 2016;11:e0164196.

20. Naudi A, Cabre R, Jove M, et al. Lipidomics of human brain aging and Alzheimer's disease pathology. Int Rev Neurobiol 2015;122:133-89.

21. Stange EF, Travis SP, Vermeire S, et al. European evidence-based Consensus on the diagnosis and management of ulcerative colitis: Definitions and diagnosis. J Crohns Colitis 2008;2:1-23.

22. Marteau P, Probert CS, Lindgren S, et al. Combined oral and enema treatment with Pentasa (mesalazine) is superior to oral therapy alone in patients with extensive mild/moderate active ulcerative colitis: a randomised, double blind, placebo controlled study. Gut 2005;54:960-5.

23. Olsen T, Goll R, Cui G, et al. Tissue levels of tumor necrosis factor-alpha correlates with grade of inflammation in untreated ulcerative colitis. Scand J Gastroenterol $2007 ; 42: 1312-1320$.

24. Magro F, Gionchetti P, Eliakim R, et al. Third European Evidence-based Consensus on Diagnosis and Management of Ulcerative Colitis. Part 1: Definitions, Diagnosis, Extraintestinal Manifestations, Pregnancy, Cancer Surveillance, Surgery, and Ileo-anal Pouch Disorders. J Crohns Colitis 2017;11:649-670.

25. Johnsen KM, Goll R, Hansen V, et al. Repeated intensified infliximab induction - results from an 11-year prospective study of ulcerative colitis using a novel treatment algorithm. Eur J Gastroenterol Hepatol 2017;29:98-104.

26. Nygren H, Seppanen-Laakso T, Castillo S, et al. Liquid chromatography-mass spectrometry (LC-MS)-based lipidomics for studies of body fluids and tissues. Methods Mol Biol 2011;708:247-57. 
27. Orikiiriza J, Surowiec I, Lindquist E, et al. Lipid response patterns in acute phase paediatric Plasmodium falciparum malaria. Metabolomics 2017;13:41.

28. Chong J, Soufan O, Li C, et al. MetaboAnalyst 4.0: towards more transparent and integrative metabolomics analysis. Nucleic Acids Research 2018;46:W486-W494.

29. Benjamini Y, Hochberg Y. Controlling the False Discovery Rate: A Practical and Powerful Approach to Multiple Testing. Journal of the Royal Statistical Society. Series B (Methodological) 1995;57:289-300.

30. Dunn OJ. Multiple Comparisons among Means. Journal of the American Statistical Association 1961;56:52-64.

31. Bonferroni CE. Teoria statistica delle classi e calcolo delle probabilitl $\{a\}$. Pubblicazioni del R Istituto Superiore di Scienze Economiche e Commerciali di Firenze 1936;8:3-62.

32. van den Berg RA, Hoefsloot HC, Westerhuis JA, et al. Centering, scaling, and transformations: improving the biological information content of metabolomics data. BMC Genomics 2006;7:142.

33. Wiklund S, Johansson E, Sjostrom L, et al. Visualization of GC/TOF-MS-based metabolomics data for identification of biochemically interesting compounds using OPLS class models. Anal Chem 2008;80:115-22.

34. Ni Y, Su M, Lin J, et al. Metabolic profiling reveals disorder of amino acid metabolism in four brain regions from a rat model of chronic unpredictable mild stress. FEBS Lett 2008;582:2627-36.

35. Fan F, Mundra PA, Fang L, et al. Lipidomic Profiling in Inflammatory Bowel Disease: Comparison Between Ulcerative Colitis and Crohn's Disease. Inflamm Bowel Dis 2015;21:1511-8. 
36. Davies JM, Hua H-U, Dheer R, et al. Stool Phospholipid Signature is Altered by Diet and Tumors. PLOS ONE 2014;9:e114352.

37. Lee Y, Choo J, Kim SJ, et al. Analysis of endogenous lipids during intestinal wound healing. PLOS ONE 2017;12:e0183028.

38. Meikle PJ, Wong G, Barlow CK, et al. Plasma Lipid Profiling Shows Similar Associations with Prediabetes and Type 2 Diabetes. PLOS ONE 2013;8:e74341.

39. Calzada E, Onguka O, Claypool SM. Phosphatidylethanolamine Metabolism in Health and Disease. In: Jeon KW, ed. International Review of Cell and Molecular Biology. Volume 321: Academic Press, 2016:29-88.

40. Elvas F, Stroobants S, Wyffels L. Phosphatidylethanolamine targeting for cell death imaging in early treatment response evaluation and disease diagnosis. Apoptosis 2017;22:971-987.

41. Delvaeye $\mathrm{T}$, Wyffels L, Deleye $\mathrm{S}$, et al. Noninvasive Whole-Body Imaging of Phosphatidylethanolamine as a Cell Death Marker Using (99m)Tc-Duramycin During TNF-Induced SIRS. J Nucl Med 2018;59:1140-1145.

42. Sassa T, Kihara A. Metabolism of Very Long-Chain Fatty Acids: Genes and Pathophysiology. Biomolecules \& Therapeutics 2014;22:83-92.

43. Kosinska MK, Liebisch G, Lochnit G, et al. Sphingolipids in human synovial fluid--a lipidomic study. PLoS One 2014;9:e91769.

44. Mielke MM, Bandaru VVR, Haughey NJ, et al. Serum ceramides increase the risk of Alzheimer disease: The Women's Health and Aging Study II. Neurology 2012;79:633641.

45. Qi Y, Jiang C, Tanaka N, et al. PPARalpha-dependent exacerbation of experimental colitis by the hypolipidemic drug fenofibrate. Am J Physiol Gastrointest Liver Physiol 2014;307:G564-73. 
46. Wang R, Gu X, Dai W, et al. A lipidomics investigation into the intervention of celastrol in experimental colitis. Mol Biosyst 2016;12:1436-44.

47. Ehehalt R, Wagenblast J, Erben G, et al. Phosphatidylcholine and lysophosphatidylcholine in intestinal mucus of ulcerative colitis patients. A quantitative approach by nanoelectrospray- tandem mass spectrometry. Scandinavian Journal of Gastroenterology 2004;39:737-742.

48. Suh JH, Degagne E, Gleghorn EE, et al. Sphingosine-1-Phosphate Signaling and Metabolism Gene Signature in Pediatric Inflammatory Bowel Disease: A Matched-case Control Pilot Study. Inflamm Bowel Dis 2018;24:1321-1334.

49. Homaidan F, E El-Sabban M, Chakroun I, et al. IL-1 stimulates ceramide accumulation without inducing apoptosis in intestinal epithelial cells, 2002.

50. Pulkoski-Gross MJ, Uys JD, Orr-Gandy KA, et al. Novel sphingosine kinase-1 inhibitor, LCL351, reduces immune responses in murine DSS-induced colitis. Prostaglandins \& Other Lipid Mediators 2017;130:47-56.

51. Snider AJ, Wu BX, Jenkins RW, et al. Loss of neutral ceramidase increases inflammation in a mouse model of inflammatory bowel disease. Prostaglandins \& Other Lipid Mediators 2012;99:124-130.

52. Florholmen J. Mucosal healing in the era of biologic agents in treatment of inflammatory bowel disease. Scand J Gastroenterol 2015;50:43-52.

53. Abdel Hadi L, Di Vito C, Riboni L. Fostering Inflammatory Bowel Disease: Sphingolipid Strategies to Join Forces. Mediators of Inflammation 2016;2016:13.

54. Raad MA, Chams NH, Sharara AI. New and Evolving Immunotherapy in Inflammatory Bowel Disease. Inflammatory intestinal diseases 2016;1:85-95. 
Figure 1. Multivariate analysis of the mucosal lipid profiles. Each subject was labeled according to the corresponding study group. Figure 2.A: 2D Principle component analysis (PCA) score plots. The variation explained by PC1 and PC2 were $25.1 \%$ and $18.5 \%$, respectively. Figure 2.B: The score plot of the OPLS-DA model built from the lipid profile of the three study groups. Figure 2.C and Figure 2.D: Score plot of the OPLS-DA model built from the lipid profile of UC treatment naïve vs healthy controls and UC treatment naïve vs UC remission patients.

Figure 2: Figure 2.A SUS-plot constructed using the correlation coefficient (p (corr)) from the loading plots of the two OPLS DA models, UC treatment-naïve vs Controls (X-axis) and UC treatment-naïve vs UC remission (Y-axis). The lipids are labelled according to lipid class. The highlighted region contains lipids that are elevated in UC treatment naïve patients. For simplicity, only a few lipids are displayed with full name. The same figure with all full names of the lipids is provided in the supplementary data section (supplementary Figure 1). Figures 3B, 3C and 3D represent the extracted ion chromatograms of $\operatorname{PE}(38: 3)$, Cer(d18:1/24:0), and $\operatorname{Cer}(\mathrm{d} 18: 1 / 24: 2)$, respectively. The peaks are aligned and colored according to the study group. Black is the treatment-naïve UC group, red is UC deep remission group, and green is healthy control group. 


\section{Tables}

Table 1. Description of study group characteristics.

\begin{tabular}{ccccc}
\hline Study Group & $\begin{array}{c}\text { Number of } \\
\text { Subjects }\end{array}$ & $\begin{array}{c}\text { Age* } \\
\text { year }\end{array}$ & $\begin{array}{c}\text { Sex } \\
\text { Female/Male }\end{array}$ & $\begin{array}{c}\text { TNF- } \alpha^{*} \\
\text { copies/ } \mu \text { g of total RNA }\end{array}$ \\
\hline Active UC (debut) & 21 & $42(20-68)$ & $6 / 15$ & $17670(4600-30700)$ \\
Healthy controls & 14 & $54(26-83)$ & $5 / 9$ & $5400(1800-13600)$ \\
UC remission & 12 & $48(23-71)$ & $4 / 8$ & $4675(800-7300)$ \\
\hline
\end{tabular}

*Data are presented as mean (range)

Table 2: Summary of altered lipids associated with UC state identified by Kruskall-Wallis and Dunn post-hoc analysis

Number of lipids

Lipid Class

Phosphatidylcholine

Ceramide

Phosphatidylserine

Phosphatidylinositol

Phosphatidylethanolamine

Galactosylceramide

Sphingomyelin

Dihydroceramide

Phosphatidylglycerol

Lysophasphatidylcholine

Lysophasphatidylethanolamine
Total number of annotated lipids
Active UC vs

Healthy Control
Active UC vs

UC Remission
UC Remission vs

Healthy Control

Total

55
27
20
14
25
20
19
17
6
12
5

\section{0}

14

11

9

10

13

10

7

1

4

2

$\begin{array}{cc}18 & 4 \\ 10 & 5 \\ 8 & 1 \\ 5 & 1 \\ 8 & 3 \\ 5 & 3 \\ 7 & 2 \\ 5 & 7 \\ 1 & - \\ - & 2 \\ - & -\end{array}$

220

122

67


Table 3: Summary performance parameters of multivariate data analysis models applied in this study.

\begin{tabular}{cccccc}
\hline Data set & Model & Components & $R^{2} \mathrm{X}_{\text {cum }}$ & $R^{2} \mathrm{Y}_{\text {cum }}$ & $\mathrm{Q}^{2}$ cum \\
\hline All 3 study groups & PCA & 2 & 0.436 & - & 0.302 \\
All 3 study groups & OPLS-DA & $2+1^{*}$ & 0.553 & 0.762 & 0.580 \\
$\begin{array}{c}\text { Active UC vs UC } \\
\text { Remission }\end{array}$ & OPLS-DA & $1+1^{*}$ & 0.403 & 0.868 & 0.788 \\
$\begin{array}{c}\text { UC Remission vs } \\
\text { Healthy Control }\end{array}$ & OPLS-DA & $1+1^{*}$ & 0.332 & 0.756 & 0.584 \\
\hline
\end{tabular}

* The number of predictive components followed by the number of orthogonal components. 

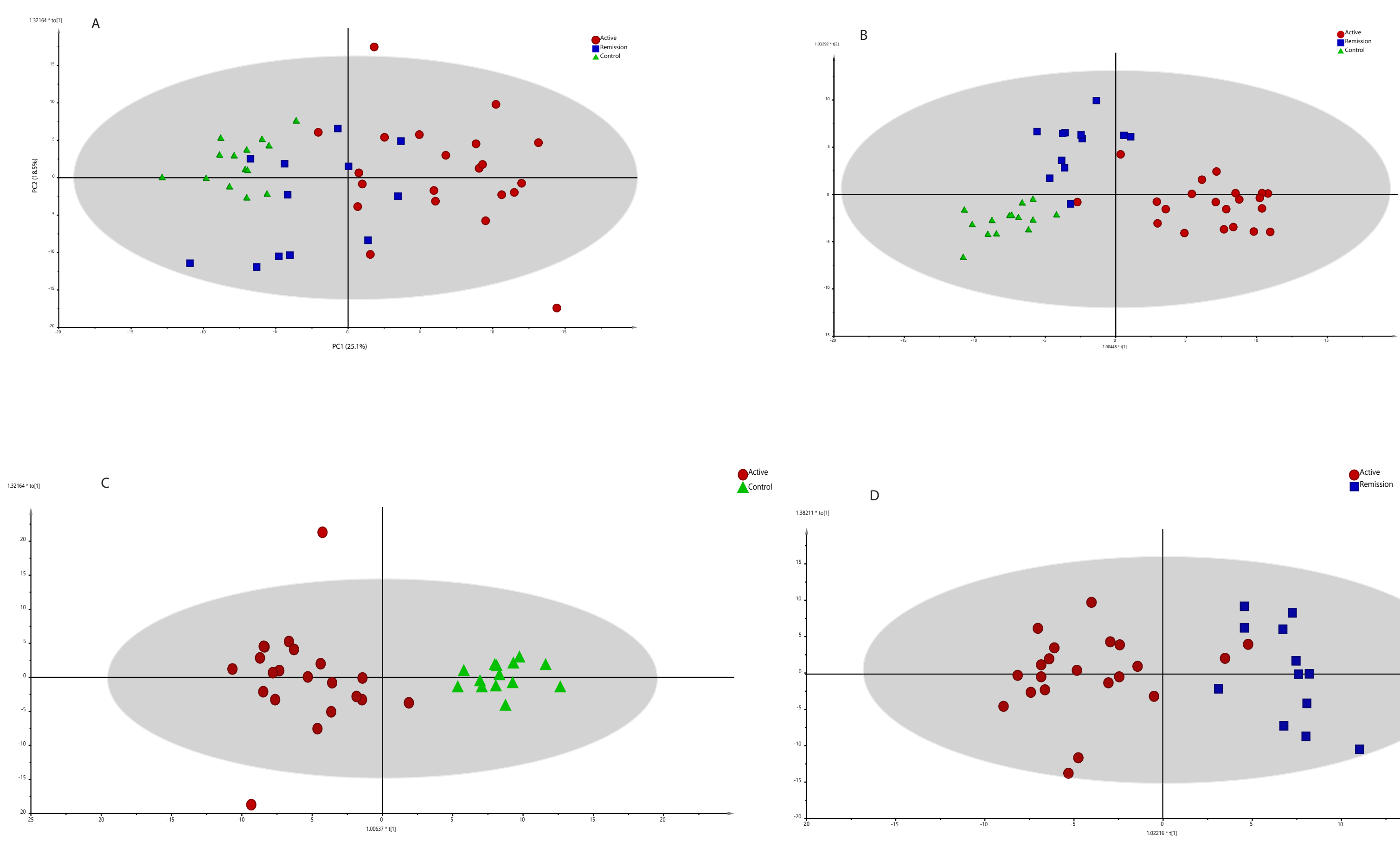

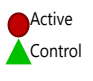

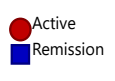

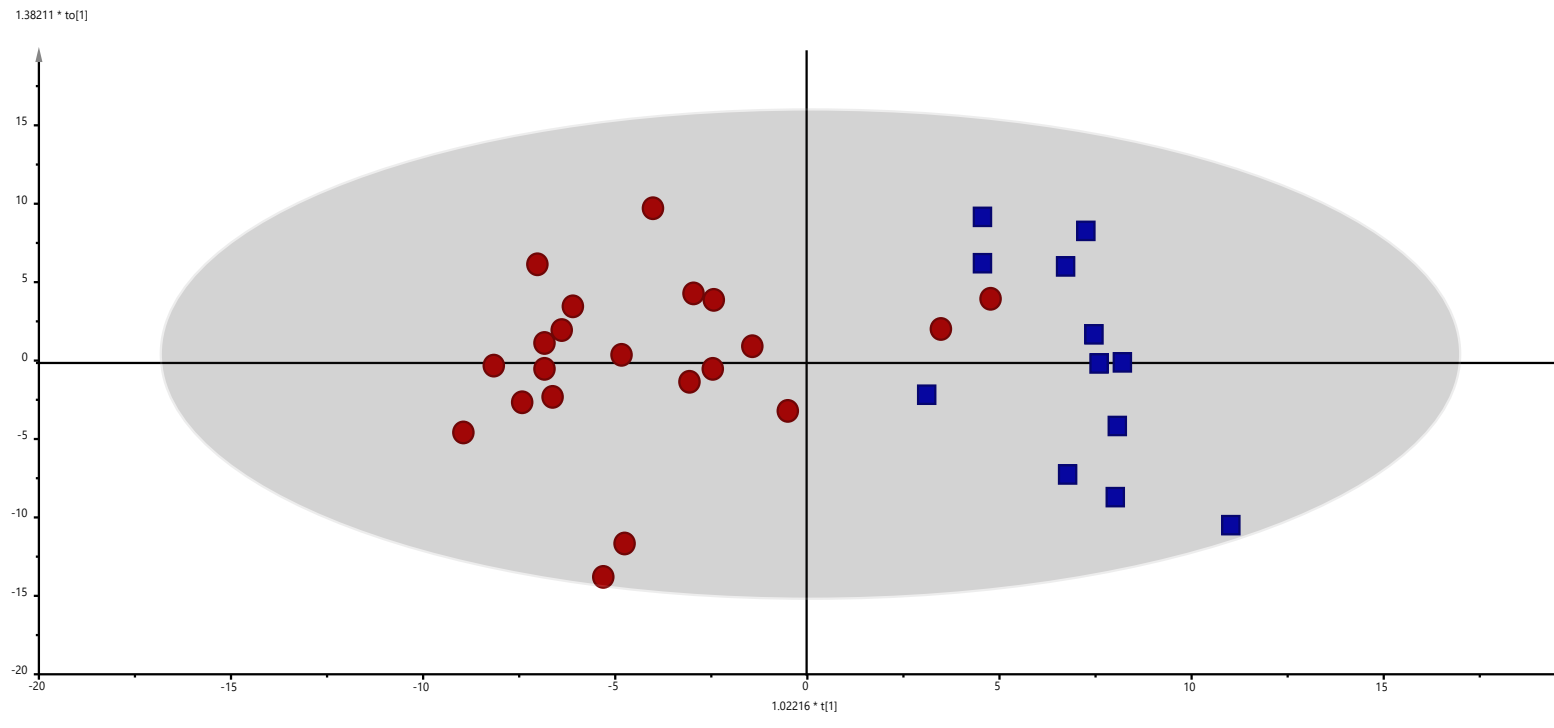



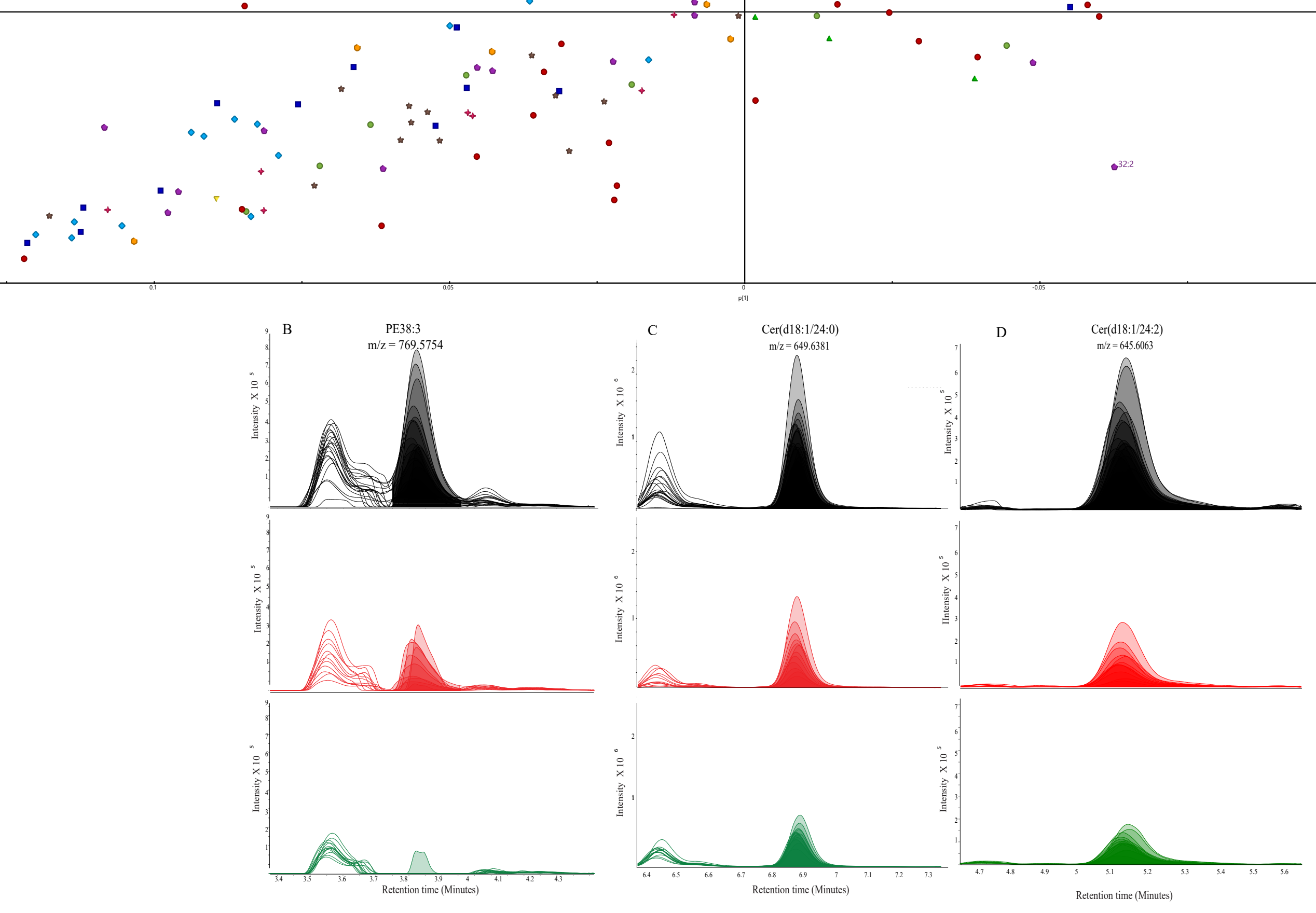
Kruskal Wallis analysis comparing lipid species composition among the study groups

\begin{tabular}{|c|c|c|c|c|c|c|c|}
\hline \multirow[b]{2}{*}{ Lipids } & \multirow[b]{2}{*}{$\begin{array}{c}\text { Kruskal Wallis } \\
\text { Test adj. p- } \\
\text { value* }\end{array}$} & \multicolumn{2}{|c|}{ Active UC vs Healthy Control } & \multicolumn{2}{|c|}{ Active UC vs Remission UC } & \multicolumn{2}{|c|}{ Remission UC vs Healthy Control } \\
\hline & & Fold change & P.value** & Fold change & P.value** & Fold change & P.value** \\
\hline Cer(d18:0/16:0) & 0.160 & 0.91 & 0.702 & 0.79 & 0.018 & 1.16 & 0.067 \\
\hline $\operatorname{Cer}(\mathrm{d} 18: 0 / 17: 0)$ & 0.099 & 0.83 & 0.063 & 0.74 & 0.016 & 1.12 & 0.565 \\
\hline Cer(d18:0/18:0) & $<0.001$ & 1.64 & $<0.001$ & 1.60 & $<0.001$ & 1.02 & 0.998 \\
\hline Cer(d18:0/19:0) & 1.000 & 1.14 & 0.279 & 0.91 & 0.625 & 1.25 & 0.162 \\
\hline Cer(d18:0/20:0) & $<0.001$ & 1.86 & $<0.001$ & 1.68 & 0.001 & 1.11 & 0.621 \\
\hline Cer(d18:0/22:0) & $<0.001$ & 1.85 & $<0.001$ & 1.92 & $<0.001$ & 0.96 & 0.739 \\
\hline Cer(d18:0/22:1) & 0.079 & 1.31 & 0.025 & 1.34 & 0.024 & 0.98 & 0.912 \\
\hline Cer(d18:0/23:0) & 0.012 & 0.83 & 0.045 & 1.36 & 0.095 & 0.61 & 0.001 \\
\hline Cer(d18:0/23:1) & 0.457 & 1.41 & 0.118 & 0.77 & 0.643 & 1.84 & 0.072 \\
\hline Cer(d18:0/23:3) & 0.452 & 1.45 & 0.075 & 1.29 & 0.161 & 1.12 & 0.784 \\
\hline $\operatorname{Cer}(\mathrm{d} 18: 0 / 24: 0)$ & 0.012 & 0.94 & 0.357 & 1.65 & 0.009 & 0.57 & 0.001 \\
\hline Cer(d18:0/24:1) & 0.011 & 1.00 & 0.349 & 1.58 & 0.009 & 0.63 & 0.001 \\
\hline Cer(d18:0/25:0) & $<0.001$ & 0.53 & $<0.001$ & 1.05 & 0.842 & 0.50 & $<0.001$ \\
\hline Cer(d18:0/25:1) & 0.002 & 0.68 & 0.006 & 1.49 & 0.139 & 0.46 & $<0.001$ \\
\hline $\operatorname{Cer}(\mathrm{d} 18: 0 / 26: 0)$ & 0.008 & 0.77 & 0.005 & 1.28 & 0.419 & 0.61 & 0.001 \\
\hline Cer(d18:0/26:1) & 0.000 & 0.64 & $<0.001$ & 1.22 & 0.273 & 0.52 & $<0.001$ \\
\hline Cer(d18:1/14:0) & 0.000 & 0.56 & 0.002 & 0.38 & $<0.001$ & 1.47 & 0.407 \\
\hline Cer(d18:1/15:1)ox & 1.000 & 0.51 & 0.736 & 0.64 & 0.986 & 0.80 & 0.755 \\
\hline Cer(d18:1/16:0) & 0.006 & 0.94 & 0.594 & 0.53 & 0.001 & 1.75 & 0.007 \\
\hline $\operatorname{Cer}(\mathrm{d} 18: 1 / 16: 1)$ & 0.000 & 0.32 & $<0.001$ & 0.38 & $<0.001$ & 0.83 & 0.317 \\
\hline $\operatorname{Cer}(\mathrm{d} 18: 1 / 17: 0)$ & 0.001 & 0.73 & 0.050 & 0.54 & $<0.001$ & 1.34 & 0.061 \\
\hline
\end{tabular}




\begin{tabular}{|c|c|c|c|c|c|c|c|}
\hline Cer(d18:1/18:0) & 0.330 & 1.04 & 0.643 & 0.80 & 0.086 & 1.29 & 0.047 \\
\hline $\operatorname{Cer}(\mathrm{d} 18: 1 / 18: 1)$ & 0.096 & 0.83 & 0.037 & 0.60 & 0.024 & 1.39 & 0.803 \\
\hline Cer(d18:1/19:0) & 0.111 & 1.21 & 0.022 & 0.96 & 0.833 & 1.26 & 0.028 \\
\hline Cer(d18:1/20:0) & 0.001 & 1.50 & $<0.001$ & 1.23 & 0.024 & 1.23 & 0.162 \\
\hline $\operatorname{Cer}(\mathrm{d} 18: 1 / 20: 1)$ & 0.014 & 1.50 & 0.001 & 1.13 & 0.341 & 1.33 & 0.047 \\
\hline $\operatorname{Cer}(\mathrm{d} 18: 1 / 20: 3)$ & 1.000 & 0.96 & 0.523 & 1.06 & 0.682 & 0.90 & 0.348 \\
\hline $\operatorname{Cer}(\mathrm{d} 18: 1 / 20: 5)$ & 0.011 & 0.93 & 0.805 & 0.58 & 0.001 & 1.61 & 0.007 \\
\hline $\operatorname{Cer}(\mathrm{d} 18: 1 / 22: 0)$ & 0.000 & 1.50 & $<0.001$ & 1.05 & 0.338 & 1.42 & 0.002 \\
\hline Cer(d18:1/22:1) & 0.000 & 2.31 & $<0.001$ & 1.92 & $<0.001$ & 1.20 & 0.332 \\
\hline Cer(d18:1/22:6) & 0.772 & 0.80 & 0.159 & 0.82 & 0.185 & 0.98 & 0.988 \\
\hline $\operatorname{Cer}(\mathrm{d} 18: 1 / 23: 0)$ & 1.000 & 1.07 & 0.212 & 1.00 & 0.998 & 1.07 & 0.275 \\
\hline Cer(d18:1/23:1) & $<0.001$ & 1.63 & $<0.001$ & 1.47 & 0.001 & 1.11 & 0.326 \\
\hline $\operatorname{Cer}(\mathrm{d} 18: 1 / 24: 0)$ & $<0.001$ & 1.51 & $<0.001$ & 1.15 & 0.052 & 1.31 & 0.006 \\
\hline Cer(d18:1/24:1) & $<0.001$ & 1.59 & $<0.001$ & 1.33 & 0.003 & 1.19 & 0.106 \\
\hline Cer(d18:1/24:1)ox & $<0.001$ & 5.96 & $<0.001$ & 4.28 & $<0.001$ & 1.39 & 0.387 \\
\hline $\operatorname{Cer}(\mathrm{d} 18: 1 / 24: 2)$ & $<0.001$ & 2.31 & $<0.001$ & 1.76 & $<0.001$ & 1.31 & 0.141 \\
\hline Cer(d18:1/25:0) & 1.000 & 1.04 & 0.672 & 1.08 & 0.319 & 0.96 & 0.586 \\
\hline Cer(d18:1/25:1) & 0.070 & 1.18 & 0.011 & 1.15 & 0.058 & 1.03 & 0.623 \\
\hline Cer(d18:1/25:2) & 0.036 & 1.31 & 0.005 & 1.03 & 0.946 & 1.27 & 0.018 \\
\hline Cer(d18:1/26:0) & 0.074 & 1.24 & 0.011 & 0.99 & 0.967 & 1.25 & 0.029 \\
\hline $\operatorname{Cer}(\mathrm{d} 18: 1 / 26: 1)$ & 0.002 & 1.31 & $<0.001$ & 1.06 & 0.797 & 1.23 & 0.003 \\
\hline Cer(d18:1/26:2) & $<0.001$ & 2.22 & $<0.001$ & 1.55 & 0.022 & 1.43 & 0.025 \\
\hline GalCer(d18:0/22:0) & 0.013 & 0.59 & 0.001 & 0.90 & 0.484 & 0.66 & 0.027 \\
\hline GalCer(d18:1/14:0) & 1.000 & 1.16 & 0.344 & 1.13 & 0.367 & 1.03 & 1.000 \\
\hline GalCer(d18:1/16:0) & 0.001 & 0.66 & 0.001 & 0.45 & 0.001 & 1.48 & 0.858 \\
\hline GalCer(d18:1/18:0)ox & $<0.001$ & 0.50 & $<0.001$ & 0.64 & 0.001 & 0.77 & 0.068 \\
\hline GalCer(d18:1/20:0) & 0.047 & 1.57 & 0.015 & 0.91 & 0.604 & 1.72 & 0.009 \\
\hline GalCer(d18:1/20:3) & 0.001 & 5.37 & $<0.001$ & 2.10 & 0.348 & 2.55 & 0.007 \\
\hline
\end{tabular}




\begin{tabular}{|c|c|c|c|c|c|c|c|}
\hline GalCer(d18:1/22:0) & 0.002 & 1.48 & $<0.001$ & 1.00 & 0.979 & 1.47 & 0.002 \\
\hline GalCer(d18:1/22:0)ox & 0.002 & 0.67 & $<0.001$ & 0.87 & 0.297 & 0.78 & 0.015 \\
\hline GalCer(d18:1/22:1) & 0.032 & 1.50 & 0.003 & 1.13 & 0.558 & 1.33 & 0.040 \\
\hline GalCer(d18:1/23:0) & 1.000 & 0.89 & 0.384 & 0.83 & 0.226 & 1.07 & 0.726 \\
\hline GalCer(d18:1/24:0) & 0.185 & 1.35 & 0.019 & 1.11 & 0.445 & 1.21 & 0.173 \\
\hline GalCer(d18:1/24:0)ox & 0.000 & 0.55 & $<0.001$ & 0.72 & 0.078 & 0.76 & 0.017 \\
\hline GalCer(d18:1/2:41) & 0.000 & 2.66 & $<0.001$ & 1.88 & 0.007 & 1.41 & 0.139 \\
\hline GalCer(d18:1/24:1)ox & 0.068 & 0.90 & 0.129 & 1.18 & 0.123 & 0.77 & 0.006 \\
\hline GalCer(d18:1/25:0)ox & 0.000 & 0.45 & $<0.001$ & 0.64 & 0.012 & 0.70 & 0.020 \\
\hline GalCer(d18:1/25:1)ox & 0.000 & 0.60 & $<0.001$ & 0.75 & 0.016 & 0.80 & 0.033 \\
\hline GalCer(d18:1/26:0)ox & 0.014 & 0.58 & 0.001 & 0.90 & 0.570 & 0.64 & 0.022 \\
\hline GalCer(d18:1/26:1) & 0.179 & 0.73 & 0.021 & 0.94 & 0.737 & 0.77 & 0.088 \\
\hline GalCer(d18:1/26:1)ox & 0.094 & 0.85 & 0.093 & 1.19 & 0.218 & 0.72 & 0.009 \\
\hline GalCer(d18:1/28:1)ox & 0.825 & 0.90 & 0.110 & 0.88 & 0.635 & 1.02 & 0.334 \\
\hline LPC (14:0) & 0.004 & 2.00 & $<0.001$ & 1.13 & 0.361 & 1.77 & 0.019 \\
\hline LPC (16:0) & 0.291 & 1.06 & 0.036 & 1.08 & 0.203 & 0.98 & 0.504 \\
\hline LPC(16:1) & 0.007 & 1.65 & 0.001 & 1.13 & 0.983 & 1.46 & 0.005 \\
\hline LPC(17:0) & 0.693 & 0.99 & 0.146 & 1.00 & 0.165 & 0.99 & 0.998 \\
\hline LPC(18:0) & 1.000 & 0.98 & 0.684 & 0.98 & 0.260 & 1.00 & 0.498 \\
\hline LPC(18:1) & 0.472 & 1.02 & 0.778 & 1.23 & 0.062 & 0.82 & 0.142 \\
\hline LPC(18:2) & 0.002 & 1.71 & $<0.001$ & 1.32 & 0.043 & 1.29 & 0.135 \\
\hline LPC(20:0) & 0.365 & 1.17 & 0.912 & 0.83 & 0.064 & 1.41 & 0.072 \\
\hline LPC $(20: 5)$ & 0.009 & 0.43 & 0.001 & 1.00 & 0.671 & 0.43 & 0.012 \\
\hline LPC(22:6) & 0.246 & 0.65 & 0.044 & 1.04 & 0.893 & 0.63 & 0.059 \\
\hline LPC(O-16:1) & 0.101 & 2.03 & 0.039 & 0.06 & 0.497 & 32.56 & 0.015 \\
\hline LPC(O-18:0) & 0.140 & 0.50 & 0.016 & 1.00 & 0.689 & 0.50 & 0.081 \\
\hline LPE(16:0) & 0.031 & 1.47 & 0.003 & 2.34 & 0.447 & 0.63 & 0.053 \\
\hline LPE(16:1) & 0.345 & 7.99 & 0.061 & 6.58 & 0.121 & 1.21 & 0.828 \\
\hline
\end{tabular}




\begin{tabular}{|c|c|c|c|c|c|c|c|}
\hline LPE(18:0) & 0.049 & 1.23 & 0.007 & 2.71 & 0.880 & 0.45 & 0.026 \\
\hline LPE(18:2) & 1.000 & 2.90 & 0.533 & 3.35 & 0.613 & 0.86 & 0.311 \\
\hline $\operatorname{LPE}(20: 0)$ & 0.000 & 0.37 & $<0.001$ & 0.40 & $<0.001$ & 0.93 & 0.635 \\
\hline $\mathrm{PC}(30: 1)$ & 0.000 & 2.49 & $<0.001$ & 1.58 & 0.029 & 1.58 & 0.078 \\
\hline $\mathrm{PC}(31: 1)$ & 0.001 & 1.49 & $<0.001$ & 1.27 & 0.018 & 1.17 & 0.254 \\
\hline $\mathrm{PC}(32: 0)$ & 0.000 & 1.69 & $<0.001$ & 1.34 & 0.008 & 1.26 & 0.010 \\
\hline $\mathrm{PC}(32: 1)$ & 0.009 & 1.27 & 0.001 & 1.03 & 0.476 & 1.24 & 0.023 \\
\hline $\mathrm{PC}(32: 2)$ & 0.008 & 1.71 & 0.001 & 1.25 & 0.130 & 1.37 & 0.105 \\
\hline $\mathrm{PC}(33: 0)$ & 0.000 & 1.90 & $<0.001$ & 1.57 & 0.001 & 1.21 & 0.137 \\
\hline $\mathrm{PC}(33: 1)$ & 1.000 & 1.02 & 0.770 & 1.09 & 0.557 & 0.94 & 0.426 \\
\hline $\mathrm{PC}(33: 2)$ & 0.001 & 0.68 & $<0.001$ & 0.74 & 0.003 & 0.93 & 0.638 \\
\hline $\mathrm{PC}(34: 0)$ & 0.000 & 1.93 & $<0.001$ & 1.64 & $<0.001$ & 1.18 & 0.541 \\
\hline $\mathrm{PC}(34: 1)$ & 0.000 & 0.83 & $<0.001$ & 0.82 & 0.002 & 1.01 & 0.646 \\
\hline $\mathrm{PC}(34: 2)$ & 0.000 & 0.78 & $<0.001$ & 0.80 & $<0.001$ & 0.98 & 0.461 \\
\hline $\mathrm{PC}(34: 3)$ & 1.000 & 0.90 & 0.472 & 0.97 & 0.889 & 0.93 & 0.615 \\
\hline $\mathrm{PC}(34: 4)$ & 0.032 & 1.79 & 0.003 & 1.25 & 0.177 & 1.43 & 0.162 \\
\hline $\mathrm{PC}(35: 0)$ & 0.002 & 1.80 & $<0.001$ & 1.52 & 0.010 & 1.18 & 0.418 \\
\hline $\mathrm{PC}(35: 1)$ & 0.094 & 0.84 & 0.029 & 1.12 & 0.604 & 0.75 & 0.017 \\
\hline $\mathrm{PC}(35: 2)$ & 0.004 & 0.70 & $<0.001$ & 0.91 & 0.424 & 0.77 & 0.016 \\
\hline $\mathrm{PC}(35: 3)$ & 0.000 & 0.57 & $<0.001$ & 0.67 & 0.006 & 0.84 & 0.163 \\
\hline $\mathrm{PC}(35: 4)$ & 0.001 & 2.50 & $<0.001$ & 1.72 & 0.014 & 1.45 & 0.212 \\
\hline $\mathrm{PC}(36: 1)$ & 1.000 & 1.01 & 0.759 & 1.16 & 0.189 & 0.88 & 0.348 \\
\hline $\mathrm{PC}(36: 2)$ & 0.000 & 0.79 & $<0.001$ & 0.84 & $<0.001$ & 0.94 & 0.123 \\
\hline $\mathrm{PC}(36: 3)$ & 0.000 & 0.82 & $<0.001$ & 0.91 & 0.241 & 0.90 & 0.002 \\
\hline $\mathrm{PC}(36: 4)$ & 0.004 & 1.26 & $<0.001$ & 1.02 & 0.750 & 1.24 & 0.006 \\
\hline $\mathrm{PC}(36: 5)$ & 0.182 & 1.15 & 0.344 & 1.52 & 0.018 & 0.76 & 0.178 \\
\hline $\mathrm{PC}(36: 6)$ & 1.000 & 0.94 & 0.996 & 1.18 & 0.242 & 0.79 & 0.280 \\
\hline $\mathrm{PC}(37: 2)$ & 0.036 & 1.34 & 0.011 & 1.39 & 0.016 & 0.96 & 0.996 \\
\hline
\end{tabular}




\begin{tabular}{|c|c|c|c|c|c|c|c|}
\hline $\operatorname{PC}(38: 3)$ & 0.001 & 1.68 & $<0.001$ & 1.55 & 0.005 & 1.09 & 0.486 \\
\hline PC(38:4) & 0.001 & 1.54 & $<0.001$ & 1.07 & 0.715 & 1.44 & 0.003 \\
\hline $\mathrm{PC}(38: 5)$ & 0.000 & 1.43 & $<0.001$ & 1.22 & 0.040 & 1.17 & 0.058 \\
\hline PC(38:6) & 0.020 & 1.45 & 0.003 & 1.33 & 0.027 & 1.09 & 0.578 \\
\hline $\mathrm{PC}(38: 7)$ & 0.874 & 1.16 & 0.354 & 1.30 & 0.127 & 0.89 & 0.554 \\
\hline $\mathrm{PC}(40: 4)$ & 0.000 & 2.59 & $<0.001$ & 2.18 & 0.003 & 1.19 & 0.458 \\
\hline $\mathrm{PC}(40: 5)$ & 0.000 & 2.07 & $<0.001$ & 1.49 & 0.057 & 1.39 & 0.057 \\
\hline $\mathrm{PC}(40: 6)$ & 0.016 & 1.49 & 0.001 & 1.16 & 0.185 & 1.28 & 0.105 \\
\hline PC(40:7) & 0.152 & 1.00 & 0.900 & 1.20 & 0.021 & 0.83 & 0.045 \\
\hline $\mathrm{PC}(40: 8)$ & 0.019 & 1.35 & 0.067 & 1.79 & 0.002 & 0.75 & 0.209 \\
\hline $\mathrm{PC}(42: 5)$ & 0.000 & 2.58 & $<0.001$ & 2.52 & 0.001 & 1.02 & 0.968 \\
\hline $\mathrm{PC}(\mathrm{O}-32: 0)$ & 0.000 & 2.07 & $<0.001$ & 1.68 & 0.001 & 1.23 & 0.303 \\
\hline $\mathrm{PC}(\mathrm{O}-32: 1)$ & 0.015 & 1.50 & 0.003 & 1.43 & 0.016 & 1.05 & 0.716 \\
\hline $\mathrm{PC}(\mathrm{O}-34: 0)$ & 1.000 & 1.10 & 0.556 & 1.16 & 0.207 & 0.95 & 0.519 \\
\hline $\mathrm{PC}(\mathrm{O}-34: 1)$ & 0.202 & 1.22 & 0.208 & 1.49 & 0.022 & 0.82 & 0.318 \\
\hline $\mathrm{PC}(\mathrm{O}-34: 2)$ & 0.001 & 0.59 & $<0.001$ & 0.82 & 0.202 & 0.73 & 0.017 \\
\hline $\mathrm{PC}(\mathrm{O}-34: 3)$ & 0.001 & 0.63 & $<0.001$ & 0.86 & 0.196 & 0.73 & 0.019 \\
\hline $\mathrm{PC}(\mathrm{O}-36: 2)$ & 0.010 & 0.72 & 0.013 & 1.24 & 0.250 & 0.58 & 0.001 \\
\hline $\mathrm{PC}(\mathrm{O}-36: 3)$ & 0.000 & 0.37 & $<0.001$ & 0.58 & 0.008 & 0.63 & 0.018 \\
\hline $\mathrm{PC}(\mathrm{O}-36: 4)$ & 0.002 & 1.44 & $<0.001$ & 1.22 & 0.060 & 1.18 & 0.119 \\
\hline $\mathrm{PC}(\mathrm{O}-36: 5)$ & 0.013 & 1.27 & 0.001 & 1.05 & 0.581 & 1.21 & 0.020 \\
\hline $\mathrm{PC}(\mathrm{O}-36: 6)$ & 0.778 & 0.77 & 0.105 & 0.91 & 0.386 & 0.85 & 0.532 \\
\hline $\mathrm{PC}(\mathrm{O}-38: 2)$ & 1.000 & 1.35 & 0.239 & 1.26 & 0.472 & 1.08 & 0.711 \\
\hline $\mathrm{PC}(\mathrm{O}-38: 3)$ & 0.000 & 1.68 & 0.010 & 2.05 & $<0.001$ & 0.82 & 0.127 \\
\hline $\mathrm{PC}(\mathrm{O}-38: 4)$ & 0.022 & 1.80 & 0.006 & 1.54 & 0.016 & 1.17 & 0.832 \\
\hline $\mathrm{PC}(\mathrm{O}-38: 5)$ & 0.114 & 1.26 & 0.013 & 1.15 & 0.126 & 1.09 & 0.445 \\
\hline $\mathrm{PC}(\mathrm{O}-38: 6)$ & 0.001 & 1.52 & $<0.001$ & 1.42 & 0.003 & 1.07 & 0.659 \\
\hline $\mathrm{PC}(\mathrm{O}-38: 7)$ & 0.264 & 1.35 & 0.028 & 1.18 & 0.330 & 1.15 & 0.302 \\
\hline
\end{tabular}




\begin{tabular}{|c|c|c|c|c|c|c|c|}
\hline $\mathrm{PC}(\mathrm{O}-40: 4)$ & 0.000 & 3.80 & $<0.001$ & 2.77 & 0.001 & 1.37 & 0.458 \\
\hline $\mathrm{PC}(\mathrm{O}-40: 6)$ & 0.000 & 1.82 & $<0.001$ & 1.59 & 0.001 & 1.14 & 0.553 \\
\hline $\mathrm{PE}(32: 0)$ & 0.028 & 1.53 & 0.003 & 1.13 & 0.630 & 1.35 & 0.030 \\
\hline $\mathrm{PE}(32: 1)$ & 0.183 & 1.43 & 0.069 & 0.77 & 0.481 & 1.86 & 0.025 \\
\hline $\mathrm{PE}(32: 2)$ & 0.003 & 1.45 & 0.076 & 0.72 & 0.017 & 2.02 & $<0.001$ \\
\hline $\mathrm{PE}(34: 0)$ & 0.018 & 1.43 & 0.002 & 1.32 & 0.094 & 1.08 & 0.221 \\
\hline $\mathrm{PE}(34: 1)$ & 0.000 & 0.67 & $<0.001$ & 0.79 & 0.010 & 0.86 & 0.107 \\
\hline $\mathrm{PE}(34: 2)$ & 0.107 & 0.82 & 0.053 & 0.80 & 0.020 & 1.03 & 0.665 \\
\hline $\mathrm{PE}(36: 1)$ & 0.174 & 0.92 & 0.036 & 1.07 & 0.794 & 0.86 & 0.038 \\
\hline $\mathrm{PE}(36: 2)$ & 0.564 & 0.87 & 0.112 & 0.96 & 0.820 & 0.91 & 0.109 \\
\hline $\mathrm{PE}(36: 3)$ & 1.000 & 0.93 & 0.988 & 1.00 & 0.509 & 0.93 & 0.553 \\
\hline $\mathrm{PE}(36: 4)$ & 0.002 & 1.54 & $<0.001$ & 1.08 & 0.561 & 1.42 & 0.006 \\
\hline $\mathrm{PE}(36: 5)$ & 0.738 & 0.81 & 0.119 & 1.05 & 0.975 & 0.77 & 0.180 \\
\hline $\mathrm{PE}(38: 0)$ & 0.026 & 0.83 & 0.002 & 0.93 & 0.107 & 0.88 & 0.235 \\
\hline $\mathrm{PE}(38: 2)$ & 0.142 & 1.31 & 0.014 & 1.10 & 0.408 & 1.20 & 0.161 \\
\hline $\operatorname{PE}(38: 3)$ & 0.000 & 37.48 & $<0.001$ & 1.96 & 0.009 & 19.13 & 0.020 \\
\hline $\mathrm{PE}(38: 4)$ & 0.002 & 1.46 & $<0.001$ & 1.16 & 0.138 & 1.26 & 0.052 \\
\hline $\mathrm{PE}(38: 5)$ & $<0.001$ & 2.17 & $<0.001$ & 1.80 & 0.005 & 1.20 & 0.205 \\
\hline $\mathrm{PE}(38: 6)$ & 1.000 & 1.03 & 0.516 & 0.89 & 0.232 & 1.16 & 0.596 \\
\hline $\mathrm{PE}(40: 4)$ & $<0.001$ & 2.66 & $<0.001$ & 1.99 & 0.005 & 1.33 & 0.168 \\
\hline $\mathrm{PE}(40: 6)$ & 1.000 & 1.13 & 0.751 & 0.98 & 0.490 & 1.16 & 0.361 \\
\hline $\mathrm{PE}(40: 7)$ & 0.790 & 1.25 & 0.114 & 1.18 & 0.324 & 1.06 & 0.632 \\
\hline $\mathrm{PE}(42: 5)$ & 0.022 & 6.27 & 0.003 & 1.16 & 0.844 & 5.42 & 0.016 \\
\hline $\mathrm{PE}(\mathrm{O}-34: 2)$ & 0.005 & 0.33 & $<0.001$ & 0.48 & 0.036 & 0.69 & 0.258 \\
\hline $\mathrm{PE}(\mathrm{O}-36: 2)$ & $<0.001$ & 0.47 & $<0.001$ & 0.84 & 0.364 & 0.56 & 0.001 \\
\hline PE(O-38:5) & $<0.001$ & 0.30 & $<0.001$ & 0.45 & 0.001 & 0.65 & 0.185 \\
\hline PG(34:1) & 0.341 & 0.92 & 0.038 & 1.04 & 0.557 & 0.89 & 0.201 \\
\hline PG(36:1) & 0.633 & 1.08 & 0.472 & 0.90 & 0.225 & 1.19 & 0.080 \\
\hline
\end{tabular}




\begin{tabular}{|c|c|c|c|c|c|c|c|}
\hline $\operatorname{PG}(38: 6)$ & 0.000 & 0.32 & $<0.001$ & 0.38 & 0.001 & 0.84 & 0.413 \\
\hline$P G(40: 7)$ & 0.236 & 0.71 & 0.029 & 0.95 & 0.753 & 0.74 & 0.104 \\
\hline $\mathrm{PG}(40: 8)$ & 0.967 & 0.81 & 0.144 & 0.95 & 0.827 & 0.86 & 0.280 \\
\hline $\mathrm{PG}(45: 8)$ & 0.357 & 1.30 & 0.046 & 1.20 & 0.217 & 1.09 & 0.538 \\
\hline $\mathrm{PI}(34: 0)$ & $<0.001$ & 2.25 & $<0.001$ & 1.40 & 0.258 & 1.61 & 0.003 \\
\hline $\begin{array}{l}\mathrm{PI}(34: 1) \\
\end{array}$ & 0.013 & 0.75 & 0.001 & 0.82 & 0.039 & 0.92 & 0.377 \\
\hline $\mathrm{PI}(34: 2)$ & 0.010 & 0.72 & 0.002 & 0.73 & 0.016 & 0.99 & 0.606 \\
\hline $\mathrm{PI}(35: 2)$ & $<0.001$ & 0.94 & 0.001 & 0.95 & $<0.001$ & 1.00 & 0.547 \\
\hline $\mathrm{PI}(36: 2)$ & $<0.001$ & 0.56 & $<0.001$ & 0.74 & 0.036 & 0.76 & 0.012 \\
\hline $\begin{array}{l}\mathrm{PI}(36: 3) \\
\end{array}$ & 1.000 & 0.88 & 0.251 & 0.92 & 0.850 & 0.95 & 0.405 \\
\hline $\begin{array}{l}\mathrm{PI}(38: 2) \\
\end{array}$ & 0.504 & 0.87 & 0.452 & 0.71 & 0.059 & 1.23 & 0.281 \\
\hline PI(38:3) & 0.001 & 1.57 & 0.001 & 1.61 & 0.001 & 0.97 & 0.940 \\
\hline $\mathrm{PI}(38: 4)$ & $<0.001$ & 1.23 & $<0.001$ & 1.07 & 0.139 & 1.15 & 0.021 \\
\hline $\mathrm{PI}(38: 5)$ & 0.367 & 1.10 & 0.205 & 1.20 & 0.049 & 0.92 & 0.483 \\
\hline PI(38:6) & 0.549 & 0.76 & 0.105 & 0.81 & 0.153 & 0.94 & 0.916 \\
\hline $\begin{array}{l}\mathrm{PI}(40: 4) \\
\end{array}$ & $<0.001$ & 1.97 & $<0.001$ & 1.63 & 0.002 & 1.21 & 0.111 \\
\hline $\mathrm{PI}(40: 5)$ & $<0.001$ & 1.59 & $<0.001$ & 1.45 & 0.002 & 1.10 & 0.309 \\
\hline $\mathrm{PI}(40: 6)$ & 1.000 & 1.13 & 0.622 & 1.23 & 0.400 & 0.91 & 0.732 \\
\hline $\mathrm{PS}(32: 1)$ & 0.689 & 0.08 & 0.094 & 0.50 & 0.771 & 0.16 & 0.230 \\
\hline PS(34:0) & $<0.001$ & 0.58 & $<0.001$ & 0.67 & 0.001 & 0.86 & 0.126 \\
\hline PS(34:1) & $<0.001$ & 0.46 & $<0.001$ & 0.36 & $<0.001$ & 1.25 & 0.769 \\
\hline $\mathrm{PS}(36: 1)$ & 0.008 & 0.70 & 0.002 & 0.72 & 0.012 & 0.98 & 0.680 \\
\hline $\mathrm{PS}(36: 2)$ & 0.101 & 0.85 & 0.080 & 0.74 & 0.014 & 1.15 & 0.473 \\
\hline $\mathrm{PS}(36: 3)$ & 0.079 & 0.88 & 0.275 & 0.67 & 0.007 & 1.32 & 0.128 \\
\hline PS(36:4) & 1.000 & 0.88 & 0.342 & 0.82 & 0.190 & 1.07 & 0.711 \\
\hline PS(38:1) & 0.515 & 1.33 & 0.073 & 1.17 & 0.229 & 1.14 & 0.641 \\
\hline $\mathrm{PS}(38: 2)$ & 0.012 & 0.77 & 0.005 & 0.72 & 0.007 & 1.07 & 0.967 \\
\hline $\mathrm{PS}(38: 3)$ & 0.032 & 1.45 & 0.017 & 1.50 & 0.009 & 0.97 & 0.766 \\
\hline
\end{tabular}




\begin{tabular}{|c|c|c|c|c|c|c|c|}
\hline $\operatorname{PS}(38: 4)$ & 0.049 & 0.72 & 0.025 & 0.51 & 0.012 & 1.40 & 0.739 \\
\hline PS(38:5) & 0.001 & 5.14 & $<0.001$ & 3.64 & 0.001 & 1.41 & 0.930 \\
\hline $\operatorname{PS}(39: 7)$ & 0.036 & 0.68 & 0.003 & 0.86 & 0.102 & 0.79 & 0.288 \\
\hline $\mathrm{PS}(40: 0)$ & 0.017 & 0.84 & 0.015 & 1.40 & 0.311 & 0.60 & 0.002 \\
\hline $\operatorname{PS}(40: 2)$ & 0.007 & 0.68 & 0.001 & 0.80 & 0.026 & 0.86 & 0.398 \\
\hline $\operatorname{PS}(40: 3)$ & 1.000 & 1.00 & 0.785 & 1.71 & 0.996 & 0.58 & 0.814 \\
\hline PS(40:4) & 0.007 & 2.00 & 0.001 & 1.22 & 0.427 & 1.64 & 0.022 \\
\hline PS(40:5) & 0.072 & 1.53 & 0.006 & 1.26 & 0.240 & 1.21 & 0.190 \\
\hline PS(40:6) & 1.000 & 1.07 & 0.255 & 0.83 & 0.197 & 1.30 & 0.849 \\
\hline $\operatorname{PS}(40: 7)$ & 0.048 & 0.78 & 0.004 & 0.91 & 0.385 & 0.86 & 0.086 \\
\hline $\mathrm{SM}(\mathrm{d} 18: 0 / 14: 0)$ & 0.006 & 1.39 & 0.006 & 1.50 & 0.002 & 0.93 & 0.640 \\
\hline SM(d18:0/16:0) & 0.070 & 0.76 & 0.008 & 0.84 & 0.092 & 0.91 & 0.442 \\
\hline $\operatorname{SM}(\mathrm{d} 18: 0 / 18: 0)$ & 1.000 & 1.03 & 0.622 & 0.97 & 0.609 & 1.06 & 0.367 \\
\hline $\operatorname{SM}(\mathrm{d} 18: 1 / 14: 0)$ & 0.010 & 1.46 & 0.002 & 1.36 & 0.018 & 1.07 & 0.575 \\
\hline $\operatorname{SM}(\mathrm{d} 18: 1 / 15: 0)$ & 0.105 & 1.24 & 0.045 & 1.29 & 0.023 & 0.96 & 0.739 \\
\hline $\operatorname{SM}(\mathrm{d} 18: 1 / 16: 0)$ & 0.170 & 0.90 & 0.042 & 0.88 & 0.051 & 1.03 & 0.993 \\
\hline $\operatorname{SM}(\mathrm{d} 18: 1 / 16: 1)$ & $<0.001$ & 1.90 & $<0.001$ & 1.61 & 0.004 & 1.18 & 0.345 \\
\hline $\operatorname{SM}(\mathrm{d} 18: 1 / 18: 0)$ & 0.000 & 0.74 & 0.001 & 0.62 & $<0.001$ & 1.19 & 0.256 \\
\hline SM(d18:1/18:0)ox & 0.331 & 1.08 & 0.376 & 1.19 & 0.036 & 0.91 & 0.249 \\
\hline $\operatorname{SM}(\mathrm{d} 18: 1 / 18: 1)$ & 0.019 & 0.81 & 0.016 & 0.64 & 0.004 & 1.26 & 0.602 \\
\hline $\operatorname{SM}(d 18: 1 / 19: 0)$ & 0.022 & 1.08 & 0.286 & 1.42 & 0.002 & 0.76 & 0.051 \\
\hline $\operatorname{SM}(\mathrm{d} 18: 1 / 20: 0)$ & 1.000 & 0.92 & 0.526 & 0.90 & 0.593 & 1.02 & 0.949 \\
\hline $\operatorname{SM}(\mathrm{d} 18: 1 / 21: 1)$ & 0.004 & 0.75 & 0.006 & 1.25 & 0.233 & 0.60 & $<0.001$ \\
\hline $\operatorname{SM}(\mathrm{d} 18: 1 / 22: 0)$ & 0.926 & 1.17 & 0.237 & 0.94 & 0.652 & 1.24 & 0.146 \\
\hline $\operatorname{SM}(\mathrm{d} 18: 1 / 23: 2)$ & 0.000 & 1.88 & $<0.001$ & 1.79 & $<0.001$ & 1.05 & 0.984 \\
\hline $\operatorname{SM}(\mathrm{d} 18: 1 / 24: 0)$ & 0.015 & 1.33 & 0.192 & 1.68 & 0.001 & 0.79 & 0.065 \\
\hline $\operatorname{SM}(\mathrm{d} 18: 1 / 24: 1)$ & 0.003 & 1.44 & $<0.001$ & 1.29 & 0.018 & 1.12 & 0.351 \\
\hline $\mathrm{SM}(\mathrm{d} 18: 1 / 24: 2)$ & $<0.001$ & 1.66 & $<0.001$ & 1.40 & 0.004 & 1.18 & 0.207 \\
\hline
\end{tabular}


* Kruskall Wallis p values adjusted by Benjamini-Hocheberg method ** Dunn post hoc test $\mathrm{p}$ values 
